\title{
Single therapeutic and supratherapeutic doses of sacubitril/valsartan (LCZ696) do not affect cardiac repolarization
}

\author{
Thomas H. Langenickel ${ }^{1}$ • Pierre Jordaan ${ }^{1} \cdot$ Jesika Petruck $^{2} \cdot$ Kiran Kode $^{3}$. \\ ${\text { Parasar } \mathrm{Pal}^{3} \text { - Soniya Vaidya }}^{4} \cdot$ Priya Chandra $^{5} \cdot$ Iris Rajman $^{1}$
}

Received: 27 January 2016 / Accepted: 10 April 2016 /Published online: 16 April 2016

(C) Springer-Verlag Berlin Heidelberg 2016

\begin{abstract}
Purpose Sacubitril/valsartan (LCZ696) is a first-in-class angiotensin receptor neprilysin inhibitor (ARNI) indicated to reduce the risk of cardiovascular death and hospitalization for heart failure in patients with chronic heart failure (NYHA class II-IV) and reduced ejection fraction. This study was aimed to evaluate the effect of single oral therapeutic (400 mg) and supratherapeutic (1200 mg) doses of LCZ696 on cardiac repolarization.

Method This randomized double-blind crossover study in healthy male subjects compared the effect of therapeutic and supratherapeutic doses of LCZ696 with placebo and moxifloxacin $400 \mathrm{mg}$ (open-label treatment) as positive control. The primary assessment was mean baseline- and placebocorrected QTcF ( $\triangle \triangle \mathrm{QTcF}$; Fridericia correction). Additional assessments included the $\triangle \Delta \mathrm{QTcB}$ (Bazett's correction), PR interval, QRS duration, heart rate (HR), LCZ696
\end{abstract}

Electronic supplementary material The online version of this article (doi:10.1007/s00228-016-2062-9) contains supplementary material, which is available to authorized users.

Thomas H. Langenickel

thomas.langenickel@novartis.com

1 Translational Medicine, Clinical Pharmacology and Profiling, Novartis Pharma AG, Basel CH-4002, Switzerland

2 Translational Medicine, Clinical Sciences and Innovation, Novartis Institutes for Biomedical Research, Cambridge, MA, USA

3 Integrated Quantitative Sciences, Novartis Healthcare Private Limited, Hyderabad, India

4 Translational Medicine, Drug Metabolism and Pharmacokinetics, Novartis Institutes for Biomedical Research, Cambridge, MA, USA

5 Translational Medicine, Drug Metabolism and Pharmacokinetics, Novartis Institutes for Biomedical Research, East Hanover, NJ, USA pharmacokinetics, pharmacokinetic/pharmacodynamic relationships, and safety.

Results Of the 84 subjects enrolled, 81 completed the study. The maximum upper bound of the two-sided $90 \%$ confidence interval for $\Delta \Delta \mathrm{QTcF}$ for LCZ696 $400 \mathrm{mg}$ and $1200 \mathrm{mg}$ were $<10 \mathrm{~ms}$, and assay sensitivity was confirmed with moxifloxacin. No relevant treatment-emergent changes were observed in any of the ECG-derived parameters with LCZ696 or placebo, and the incidence of adverse events was comparable among the treatment groups.

Conclusion Single therapeutic and supratherapeutic doses of LCZ696 did not affect cardiac repolarization as defined by the E14 ICH guidelines.

Keywords Angiotensin receptor neprilysin inhibitor · Cardiac repolarization · Heart failure · LCZ696 - QT prolongation · Sacubitril/valsartan

\section{Introduction}

Sacubitril/valsartan (LCZ696) is a first-in-class angiotensin receptor neprilysin inhibitor (ARNI) indicated to reduce the risk of cardiovascular death and hospitalization for heart failure in patients with chronic heart failure (NYHA class II-IV) and reduced ejection fraction (HFrEF) [1, 2]. Following oral administration, LCZ696 provides systemic exposure to the pro-drug sacubitril (also known as AHU377, which is further metabolized to the active neprilysin inhibitor LBQ657) and valsartan [3]. The mechanism of the beneficial effects of LCZ696 in HF are believed to be due to the enhancement of protective endogenous neurohormonal systems, such as the natriuretic peptide (NP) system, in the presence of simultaneous inhibition of the deleterious effects related to sustained renin-angiotensin-aldosterone system (RAAS) activation. 
Drug-induced delayed cardiac repolarization, as reflected by a prolongation of the rate-corrected QT interval $(\mathrm{QTc})$ is an important cardiac safety finding leading to the withdrawal of numerous drugs from the market $[4,5]$. Drugs that have potential to block the rapid component of the delayed rectifier potassium channel $\left(\mathrm{I}_{\mathrm{KR}}\right)$ coded by human Ether-à-go-go related gene (hERG) can prolong QTc, which may lead to increased susceptibility to cardiac arrhythmias, notably Torsades de Pointes $[4,6,7]$. Therefore, rigorous characterization of novel pharmaceutical agents for their potential to prolong the QTc interval is warranted as part of their cardiac safety assessment.

Clinical and experimental evidence corroborate the beneficial effects of chronic treatment with RAAS inhibitors on the duration of QT interval in patients with hypertension and HF [8]. While this may reflect the end result of several indirect factors, the impact of RAAS inhibitors on the electrophysiological mechanisms altered by angiotensin II might be a possible reason [9]. Angiotensin II probably prolongs the action potential by inhibiting the rapidly activating components of $\mathrm{I}_{\mathrm{KR}}$ [10]. The beneficial effect of valsartan in HF is clinically evident, while sacubitril showed no relevant effect on the $\mathrm{hERG} / \mathrm{I}_{\mathrm{KR}}$ channel current even at the highest LCZ696 concentration tested ( $3000 \mu \mathrm{M} ;<50 \%$ inhibition) in vitro (data on file). Although in vitro ion-channel assessment of LBQ657 was not performed, QT prolongation was not documented during systematic in vivo exposure in primates (LCZ696) and dogs (sacubitril). This study therefore provided a dedicated assessment of effects of single oral therapeutic $(400 \mathrm{mg})$ and supratherapeutic $(1200 \mathrm{mg})$ doses of LCZ696 on cardiac repolarization to support the use in patients with HF.

\section{Methods}

\section{Subjects}

Healthy male subjects $18-45$ years of age with a body weight $\geq 60 \mathrm{~kg}$, a body mass index (BMI) of $18-28 \mathrm{~kg} / \mathrm{m}^{2}$, and normal ECG, vital signs, and laboratory tests were enrolled in the study. The key exclusion criteria were use of other investigational drugs within 30 days of enrollment or within five halflives of treatment, contraindications to the use of moxifloxacin, a history of angioedema or drug/alcohol abuse, or donation or loss of $\geq 400 \mathrm{~mL}$ of blood within 8 weeks before initial dosing. All subjects provided written informed consent before starting any of the study-related procedures.

\section{Study design}

This was a single-center, randomized, positive- and placebocontrolled, partially blinded, single-dose study with a $4 \times 3$ Williams crossover design with 12 treatment sequences (Fig. 1). Following a screening period of up to 21 days, eligible subjects entered the randomized double-blind treatment periods consisting of four 48 -h treatment periods separated by washout periods of $\geq 4$ days each. The final study completion evaluation was performed 4-10 days after the last treatment. Subjects were admitted at least $35 \mathrm{~h}$ before treatment in each treatment period for baseline assessments including 24-h ECG Holter recording and were permitted to leave the center during the washout periods.

The subjects were randomized to one of the 12 treatment sequences and received four treatments: single oral doses of LCZ696 $400 \mathrm{mg}$ (therapeutic dose), LCZ696 $1200 \mathrm{mg}$ (supratherapeutic dose), placebo, or moxifloxacin $400 \mathrm{mg}$. Treatments with LCZ696 and placebo were blinded, whereas moxifloxacin treatment was administered in an open-label manner.

Food and beverages that could potentially impact the PK of LCZ696 analytes or ECG measurements, such as citrus fruits, grapefruit, and quinine (e.g., tonic water), were restricted within 3 days before or during treatment periods, while alcohol and substances containing methylxanthines (e.g., caffeine, cola, chocolate) were restricted $10 \mathrm{~h}$ before the start of the continuous ECG measurement and during the clinic stay of each treatment period.

The study protocol was approved by the Ethics Committee of the study center. The study was designed and implemented in accordance with the ICH Guidelines for Good Clinical Practice E6 [11] and for Clinical Evaluation of QT/QTc Interval Prolongation and Proarrhythmic Potential for NonAntiarrhythmic Drugs E14 [12], applicable local regulations, and the ethical principles laid down in the Declaration of Helsinki.

\section{Pharmacodynamic assessments}

The primary assessment was the mean baseline- and placebocorrected Fridericia-corrected QT $(\Delta \Delta \mathrm{QTcF})$. The secondary assessments included the $\Delta \Delta \mathrm{QTcB}$ (Bazett's correction); QTcF and QTcB assay sensitivity with moxifloxacin; proportion of subjects with notable changes in corrected $(\mathrm{QTcF}$ and QTcB) and uncorrected QT (defined as an increase of $>30$ or $>60 \mathrm{~ms}$ from baseline or a change to $>450,>480$, or $>500 \mathrm{~ms}$, if the condition not existed at baseline); changes in PR interval, QRS duration, and HR and the proportion of subjects with notable changes from baseline in these parameters defined as $40>\mathrm{HR}>100, \mathrm{PR}>200$, and $\mathrm{QRS}>110 \mathrm{~ms}$ in the presence of $25 \%$ change from pretreatment.

Continuous 24-h Holter ECGs were collected at baseline and following drug administration in each treatment period. ECGs were extracted from the Holter recordings at $-1 \mathrm{~h},-35 \mathrm{~min}$, and $-15 \mathrm{~min}$ for baseline, and at $0.5,1,2,3,4,5,8,12$, and $24 \mathrm{~h}$ relative to the dosing time for post-dose assessment. ECGs were analyzed in a blinded fashion in a central ECG laboratory (iCardiac Technologies Inc., Rochester, NY, USA). 


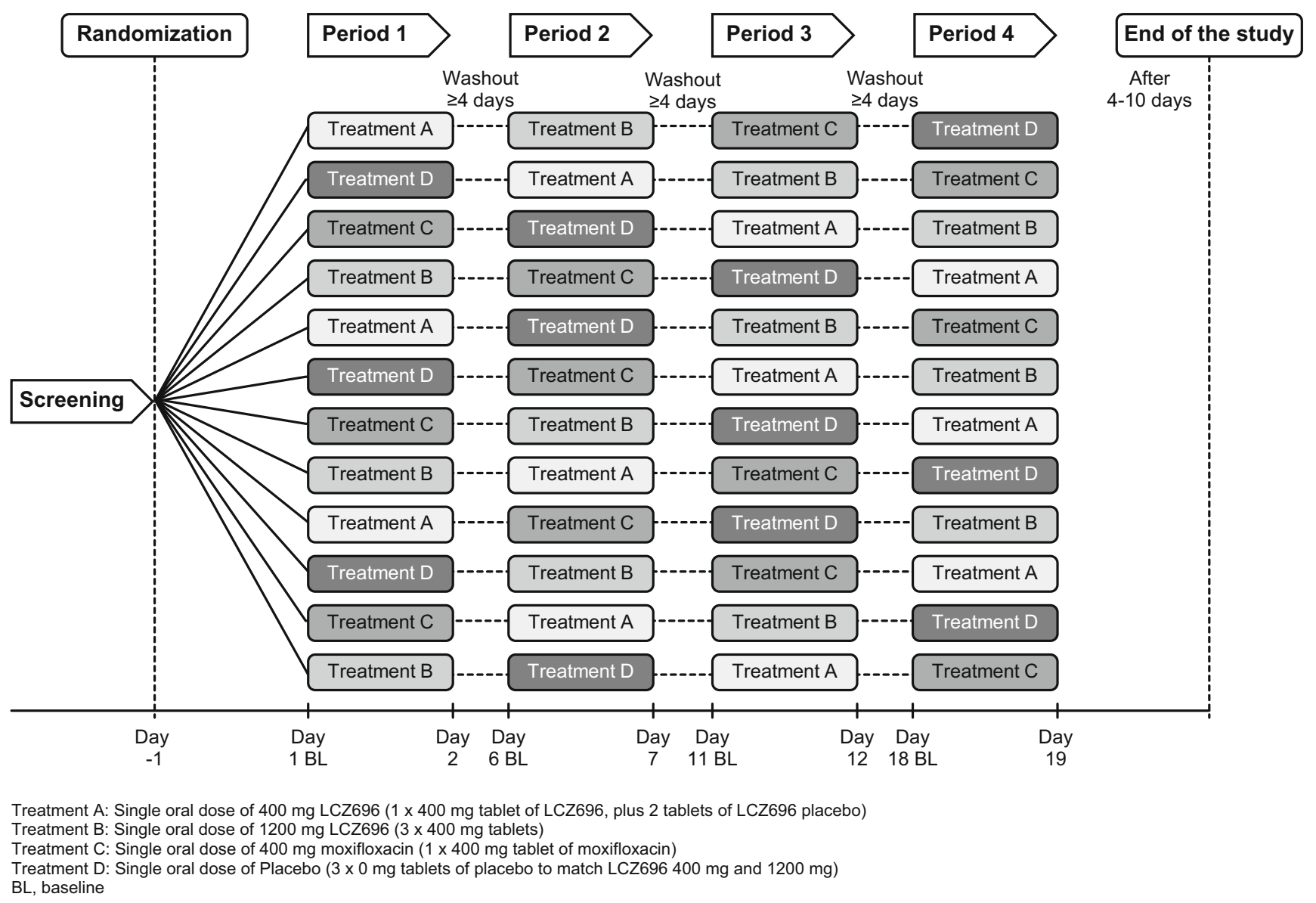

Fig. 1 Study design. Treatment A: Single oral dose of $400 \mathrm{mg} \mathrm{LCZ696}$ ( $1 \times 400 \mathrm{mg}$ tablet of LCZ696, plus 2 tablets of LCZ696 placebo). Treatment B: Single oral dose of $1200 \mathrm{mg} \mathrm{LCZ696}(3 \times 400 \mathrm{mg}$ tablets). Treatment $C$ : Single oral dose of $400 \mathrm{mg}$ moxifloxacin

\section{Pharmacokinetic assessments}

The pharmacokinetic (PK) parameters including peak plasma drug concentration $\left(\mathrm{C}_{\max }\right)$, time to reach $\mathrm{C}_{\max }\left(\mathrm{T}_{\max }\right)$, area under the plasma concentration-time curve from 0 to $24 \mathrm{~h}$ post-dose $\left(\mathrm{AUC}_{0-24 \mathrm{~h}}\right)$, and $\mathrm{AUC}$ up to the last measurable concentration $\left(\mathrm{AUC}_{\text {last }}\right)$ for sacubitril, $\mathrm{LBQ} 657$ and valsartan were determined by noncompartmental methods using WinNonlin Phoenix version 6.2 (Pharsight Corporation, Mountain View, CA). The exposureresponse relationship for QTcF during LCZ696 treatment was also assessed.

For the assessments of PK parameters, serial blood samples were collected at predose and $0.5,1,2,3,4,5,8,12$, and $24 \mathrm{~h}$ post-dose. Plasma was obtained at each time point and kept frozen at $\leq-15{ }^{\circ} \mathrm{C}$ until analysis. Quantification of sacubitril, LBQ657, and valsartan in plasma was performed using a validated liquid chromatography tandem mass spectroscopy (LCMS/MS) method [3]. The lower limits of quantification for sacubitril, LBQ657, and valsartan were 1.00, 20.0, and $10.0 \mathrm{ng} / \mathrm{mL}$, respectively.
$(1 \times 400 \mathrm{mg}$ tablet of moxifloxacin). Treatment $D$ : Single oral dose of placebo $(3 \times 0 \mathrm{mg}$ tablets of placebo to match LCZ696 $400 \mathrm{mg}$ and $1200 \mathrm{mg}) . B L$, baseline

\section{Safety}

Safety assessments included monitoring of all adverse events (AEs) and serious AEs (SAEs) and their relationship to study drugs. Vital signs and laboratory parameters were assessed at regularly intervals, and additional safety ECGs were collected and assessed to confirm subject safety during profile days.

\section{Statistical analyses}

A total of 84 subjects were planned to be randomized, assuming a dropout rate of $<10 \%$, to complete all the four treatment periods of the study with at least 73 subjects. This would provide $\geq 80 \%$ power to obtain the upper bound of the twosided $90 \%$ confidence interval $(\mathrm{CI})$ for the comparison between LCZ696 and placebo below $10 \mathrm{~ms}$, when the true difference between the two treatments was $\leq 4 \mathrm{~ms}$, assuming a standard deviation (SD) of change from baseline in QTc of $<11.5 \mathrm{~ms}$.

The safety analysis set included all subjects receiving at least one dose of the study drug. The PD analysis set included 
all subjects with available PD data and no protocol deviations that could have an impact on the PD data. The PK analysis set included all subjects who received the study drug with at least one available valid PK concentration without protocol deviations that could have a relevant impact on the PK data.

For the assessment of the primary objective of the study, the effects of single therapeutic and supratherapeutic doses of LCZ696 on QTcF were compared with placebo using onesided $t$ tests at the level of $\alpha=0.05$ as per the requirements of the ICH E14 guidelines [12]. The null hypothesis under consideration was a change from baseline of placebocorrected QTc $(\Delta \Delta \mathrm{QTcF})>10 \mathrm{~ms}$ for at least one time point. The lack of effect on QTc was considered to be established upon the rejection of the null hypotheses, that is, if the upper bound of all two-sided $90 \%$ confidence intervals (or onesided $95 \%$ upper bound) of $\Delta \Delta \mathrm{QTcF}$ values at all the time points were below $10 \mathrm{~ms}$ for LCZ696. Assay sensitivity was concluded if the $p$ value for at least one of the 4 comparisons at the 1,2,3, and $4 \mathrm{~h}$ post-dose time points for moxifloxacin was $<0.0125$ (Bonferroni correction).

Goodness-of-fit (best fit) graphs plotted to determine the performance of the QT correction formulas, based on the predose QTc-RR relationship (Supplementary Fig. S1), suggest the Fridericia correction method (QTcF) as an appropriate method as the Bazett correction method (QTcB) tended to overcorrect at elevated HR. The PK-PD relationship was evaluated using a linear mixed-effect model.

\section{Results}

\section{Subjects}

Of the total 84 randomized subjects, 81 subjects completed the study, with treatment noncompliance (one subject), difficulty in swallowing the tablet (one subject), and withdrawal of consent (one subject) being the reasons for discontinuations. The mean age of the enrolled subjects was 32.8 years, all subjects were men and majority of the subjects were Caucasians (96.4\%), and mean (standard deviation) weight was $79.0(8.81) \mathrm{kg}$ and a BMI of $24.5(2.27) \mathrm{kg} / \mathrm{m}^{2}$ (Supplementary Table 1 ).

\section{Pharmacodynamic assessments}

The maximum mean $\triangle \Delta \mathrm{QTcF}$ following the administration of LCZ696 400 and $1200 \mathrm{mg}$ was 2.9 and $3.6 \mathrm{~ms}$, respectively, observed at $1 \mathrm{~h}$ post-dose. The upper bound of the two-sided $90 \% \mathrm{CI}$ for all the $\Delta \Delta \mathrm{QTcF}$ values remained below the $10 \mathrm{~ms}$ threshold, with a maximum upper bound of $3.9 \mathrm{~ms}$ observed at $2 \mathrm{~h}$ post-dose for LCZ696 $400 \mathrm{mg}$, and $4.5 \mathrm{~ms}$ observed at $1 \mathrm{~h}$ post-dose for LCZ696 $1200 \mathrm{mg}$ (Fig. 2a). The baseline- corrected QTcF $(\triangle \mathrm{QTcF})$ comparing all treatments with placebo is presented in Fig. 2b.

Following moxifloxacin administration, the maximum mean $\triangle \Delta \mathrm{QTcF}$ at $1 \mathrm{~h}$ post-dose was $11.9 \mathrm{~ms}$, and the lower bounds of the two-sided $90 \%$ CIs for $\Delta \Delta \mathrm{QTcF}$ was $>0 \mathrm{~ms}$ at all predefined post-dose time points, thereby confirming assay sensitivity.

The mean changes in HR, PR interval, and QRS duration from baseline by time and treatment are presented in Supplement Fig. S2a, b, c. The maximal mean HR increase from baseline was observed at $8 \mathrm{~h}$ after administration of LCZ696 $400 \mathrm{mg}$ (10.5 bpm) and LCZ696 $1200 \mathrm{mg}$ (11.4 bpm), and $12 \mathrm{~h}$ after administration of moxifloxacin and placebo (6.9 and $6.3 \mathrm{bpm}$, respectively). There were no treatment-related relevant changes in the mean PR interval and QRS duration in any of the treatment groups.

\section{Notable changes in ECG parameters}

The proportions of subjects with treatment-emergent notable changes in ECG parameters are presented in Supplementary Table 2. No subject had treatment-emergent QTcF or uncorrected QT values of $>480 \mathrm{~ms}$ or $>500 \mathrm{~ms}$, or an increase from baseline by $>60 \mathrm{~ms}$. Treatment-emergent QTcF $>450 \mathrm{~ms}$ occurred only in one subject receiving moxifloxacin from 1 to $5 \mathrm{~h}$ post-dose, while an uncorrected QT $>450 \mathrm{~ms}$ was observed in $1(1.2 \%)$ subject receiving LCZ696 $400 \mathrm{mg}$ and in $3(3.7 \%)$ subjects receiving moxifloxacin. An increase in corrected QT from baseline by 30-60 ms was observed only in the moxifloxacin group (2 [2.5\%]). No treatment-emergent notable events related to changes in HR, PR interval, or QRS duration were noted during LCZ696 treatment. In addition, no changes in ECG related to repolarization or morphology were noted during LCZ696 treatment.

\section{Pharmacokinetic assessments}

Pharmacokinetics of sacubitril, LBQ657, and valsartan following the administration of single oral doses of LCZ696 400 or $1200 \mathrm{mg}$ under fasting condition are summarized in Table 1. The mean plasma concentrations of sacubitril increased rapidly with a median $\mathrm{T}_{\max }$ of $0.52 \mathrm{~h}$ for the $400 \mathrm{mg}$ dose and $1.05 \mathrm{~h}$ for the $1200 \mathrm{mg}$ dose, followed by LBQ657, with the corresponding $\mathrm{T}_{\max }$ values of 2.07 and $3.05 \mathrm{~h}$, respectively. The median $\mathrm{T}_{\max }$ for valsartan was $2.07 \mathrm{~h}$ for both the LCZ696 $400 \mathrm{mg}$ and $1200 \mathrm{mg}$ doses. The $\mathrm{C}_{\max }$ of LBQ657 showed a dose proportional increase, while the $\mathrm{C}_{\max }$ of sacubitril and valsartan showed less than proportional increases between the doses. The arithmetic mean $\mathrm{AUC}_{0-24 \mathrm{~h}}$ and $\mathrm{AUC}_{\text {last }}$ for sacubitril and LBQ657 increased approximately dose proportionally, but showed less than dose proportional increase for valsartan. 


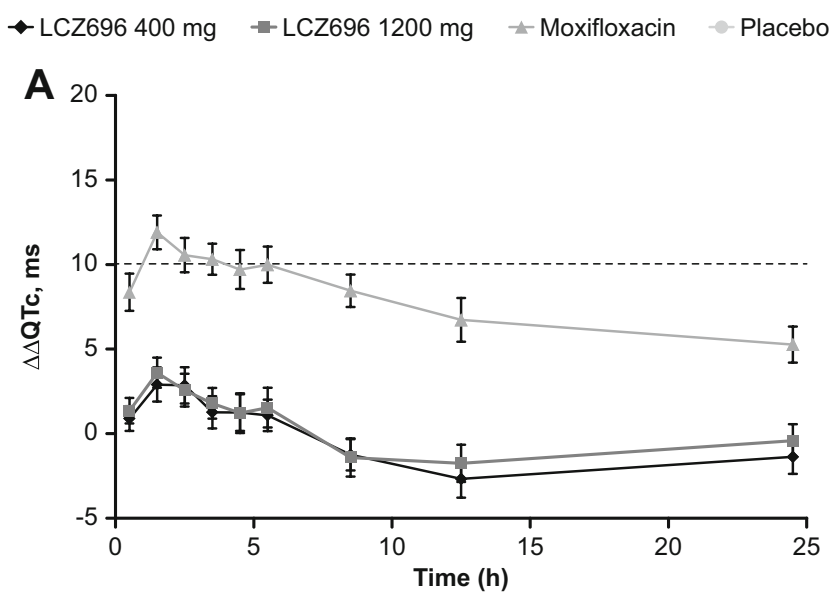

\section{Pharmacokinetic and pharmacodynamics relationship}

The estimated regression of plasma concentrations of LCZ696 analytes against $\Delta \Delta \mathrm{QTcF}$ and the corresponding $90 \% \mathrm{CI}$ (shaded area) are presented in Fig. 3. The upper bounds of the model-predicted $90 \% \mathrm{CI}$ of the regression equation for $\triangle \triangle \mathrm{QTCF}$ were below $10 \mathrm{~ms}$ for all LCZ696 analytes, except for sacubitril at concentrations $>15000 \mathrm{ng} / \mathrm{mL}$. The mean $\mathrm{C}_{\max }$ of sacubitril following administration of a single therapeutic dose of $400 \mathrm{mg}$ LCZ696 was $3210 \mathrm{ng} / \mathrm{mL}$.

\section{Safety}

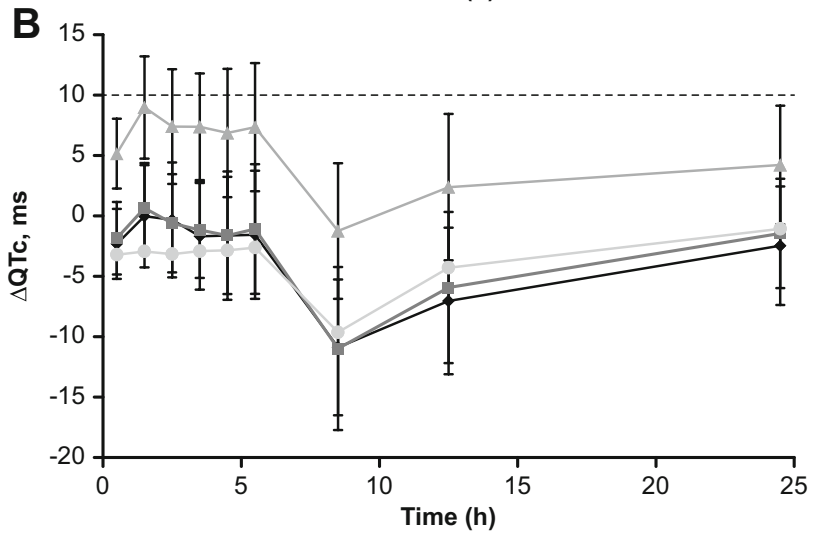

Of the 84 subjects enrolled and randomized, 29 subjects (34.5\%) experienced at least one AE during the study (Supplement Table 3). The overall incidence of AEs was comparable across the treatment groups (LCZ696 $400 \mathrm{mg}$ [14.6\%], LCZ696 $1200 \mathrm{mg}$ [14.6\%], moxifloxacin $400 \mathrm{mg}$ [13.6\%], and placebo [12.2\%]). Headache, nasopharyngitis, postural dizziness, and nausea were the most commonly reported AEs. Majority of the AEs were of mild intensity and resolved without any treatment. No deaths or SAEs were reported during the study, and none of the AEs led to study discontinuation of a subject. There were no clinically significant changes in laboratory measurements, vital signs, and safety ECGs.

Fig. 2 QTcF following administration of LCZ696 $400 \mathrm{mg}, 1200 \mathrm{mg}$, moxifloxacin $400 \mathrm{mg}$, and placebo by time point: a Baseline- and placebo-corrected QTcF $(\Delta \Delta \mathrm{QTcF})$ and $\mathbf{b}$ baseline-corrected $\mathrm{QTcF}$ $(\triangle \mathrm{QTcF})$. Data are mean $\pm 95 \%$ confidence intervals

\section{Discussion}

Patients with heart failure have an impaired repolarization reserve [13], in addition to several other factors that may

Table 1 Pharmacokinetics of LCZ696 analytes following administration of therapeutic $(400 \mathrm{mg})$ and supratherapeutic doses (1200 mg) of LCZ696

\begin{tabular}{|c|c|c|c|c|c|c|}
\hline \multirow[t]{2}{*}{ Parameter } & \multicolumn{3}{|c|}{ LCZ696 $400 \mathrm{mg}$} & \multicolumn{3}{|c|}{ LCZ696 $1200 \mathrm{mg}$} \\
\hline & $N$ & Arithmetic mean (SD) & $\mathrm{CV} \%$ & $N$ & Arithmetic mean (SD) & $\mathrm{CV} \%$ \\
\hline \multicolumn{7}{|l|}{ Sacubitril } \\
\hline $\mathrm{AUC}_{0-24 \mathrm{~h}}, \mathrm{~h} * \mathrm{ng} / \mathrm{mL}$ & 81 & $4400(1780)$ & 40.4 & 82 & $13200(4640)$ & 35.3 \\
\hline $\mathrm{AUC}_{\text {last }}, \mathrm{h} * \mathrm{ng} / \mathrm{mL}$ & 82 & $4390(1760)$ & 40.2 & 82 & $13100(4640)$ & 35.3 \\
\hline $\mathrm{C}_{\max }, \mathrm{ng} / \mathrm{mL}$ & 82 & $3210(1690)$ & 52.6 & 82 & $7780(3830)$ & 49.2 \\
\hline $\mathrm{T}_{\max }, \mathrm{h}^{\mathrm{a}}$ & 82 & $0.52(0.50,3.08)$ & & 82 & $1.05(0.48,4.0)$ & \\
\hline \multicolumn{7}{|l|}{ LBQ657 } \\
\hline $\mathrm{AUC}_{0-24 \mathrm{~h}}, \mathrm{~h} * \mathrm{ng} / \mathrm{mL}$ & 81 & $122000(19700)$ & 16.2 & 82 & $364000(62300)$ & 17.1 \\
\hline $\mathrm{AUC}_{\text {last }}, \mathrm{h}$ *ng/mL & 82 & $121000(22200)$ & 18.3 & 82 & $364000(62400)$ & 17.1 \\
\hline $\mathrm{C}_{\max }, \mathrm{ng} / \mathrm{mL}$ & 82 & $13700(2490)$ & 18.2 & 82 & $40700(6990)$ & 17.2 \\
\hline $\mathrm{T}_{\max }, \mathrm{h}^{\mathrm{a}}$ & 82 & $2.07(1.05,5.07)$ & & 82 & $3.05(2.05,5.07)$ & \\
\hline \multicolumn{7}{|l|}{ Valsartan } \\
\hline $\mathrm{AUC}_{0-24 \mathrm{~h}}, \mathrm{~h} * \mathrm{ng} / \mathrm{mL}$ & 81 & $30500(14500)$ & 47.5 & 82 & $66000(25400)$ & 38.5 \\
\hline $\mathrm{AUC}_{\text {last }}, \mathrm{h} * \mathrm{ng} / \mathrm{mL}$ & 82 & $30300(14500)$ & 47.9 & 82 & $66000(25400)$ & 38.5 \\
\hline $\mathrm{C}_{\max }, \mathrm{ng} / \mathrm{mL}$ & 82 & $4690(2210)$ & 47.2 & 82 & $9360(3790)$ & 40.5 \\
\hline $\mathrm{T}_{\max }, \mathrm{h}^{\mathrm{a}}$ & 82 & $2.07(1.05,5.07)$ & & 82 & $2.07(1.03,4.07)$ & \\
\hline
\end{tabular}

$A U C_{0-24 h}$ area under the plasma concentration-time curve from 0 to $24 \mathrm{~h}$ post-dose, $A U C_{\text {last }}$ AUC up to the last measured concentration, $C_{\max }$ peak plasma drug concentration, $C V$ coefficient of variance, $S D$ standard deviation, $T_{\max }$ time to reach $\mathrm{C}_{\max }$

${ }^{\mathrm{a}}$ Data are presented as median (range) 
Fig. 3 Pharmacokinetic/ pharmacodynamic relationship following LCZ696 administration for a sacubitril, b LBQ657, and c valsartan. Dashed line denotes the 10 -ms threshold; shaded area represents corresponding $90 \%$ confidence interval of mean change
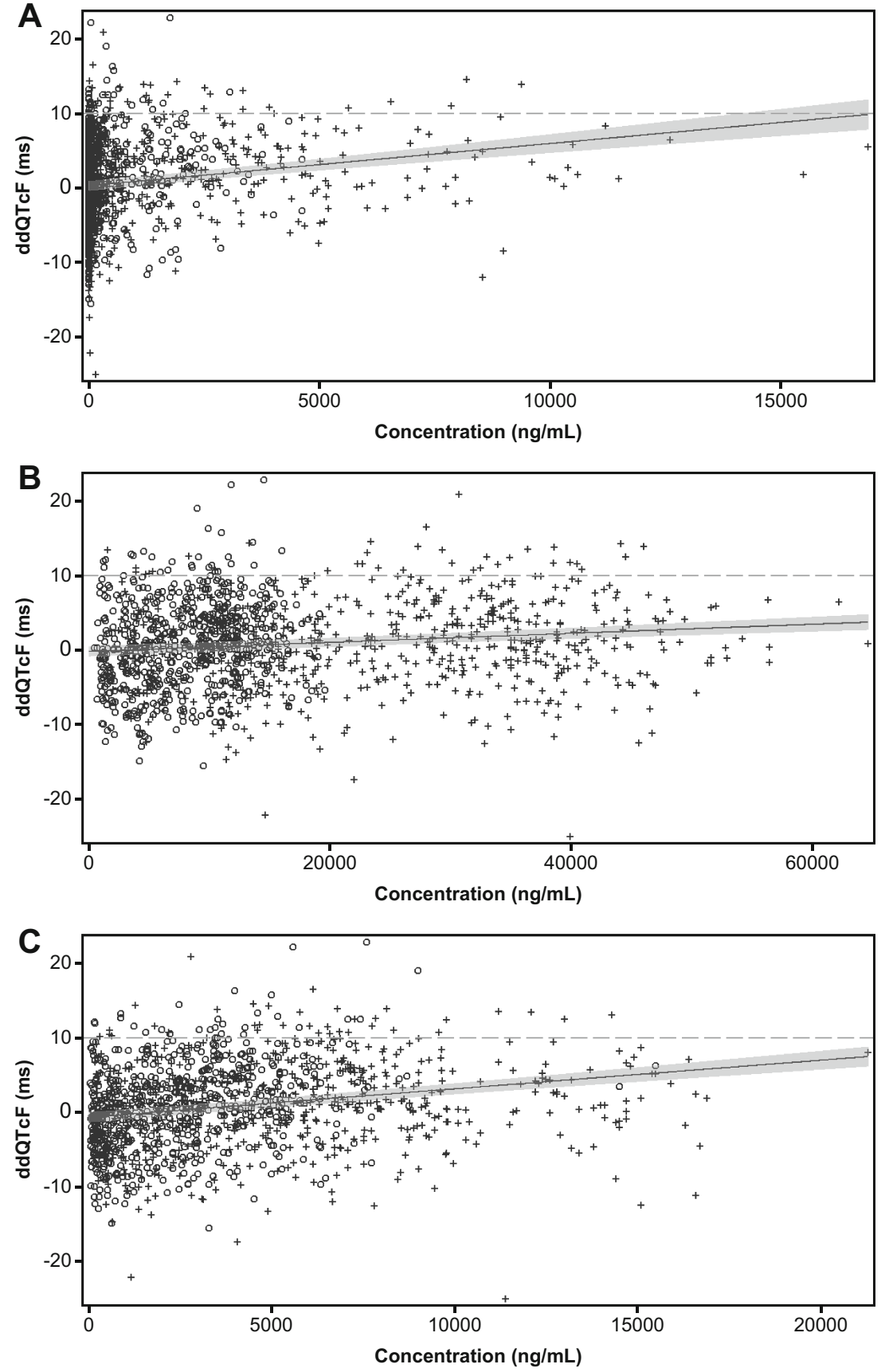

Dashed line denotes the $10 \mathrm{~ms}$ threshold; shaded area represents corresponding $90 \%$ confidence interval of mean change predispose them and contribute to potentially life-threatening cardiac arrhythmias, including autonomic imbalance, electrolyte abnormalities, and QT-prolonging co-treatments. They are also at significantly increased risk for malignant ventricular death and sudden death [14].

LCZ696 is a novel drug approved for the treatment of HFrEF. According to ICH E14 guidelines, a thorough assessment of its effects on cardiac repolarization is required. Whereas the autonomic and neurohormonal milieu present in patients with HF differs substantially from healthy subjects, the TQT study environment provides the optimally standardized environment required to identify modest underlying changes in cardiac repolarization, and studies in healthy subjects are generally considered acceptable to inform drugrelated repolarization liability [12].

This study evaluated the effect of LCZ696 $400 \mathrm{mg}$, representing the total daily dose of the highest approved clinical dose and regimen (200 mg twice daily), and $1200 \mathrm{mg}$, representing a 6-fold multitude of any given single dose and 3 -fold multiple of the standard total daily dose. Plasma 
concentrations observed in the present QTc study exceeded observed steady-state plasma concentration in healthy subjects and patients with heart failure. Furthermore, all LCZ696 analytes have a short half-life, high-plasma protein binding and were fully characterized regarding their effect on the QTc interval, thereby justifying a single-dose study design and the selected doses.

The results indicate no relevant impact on cardiac repolarization with LCZ696 at either doses as evidenced by a mean $\Delta \triangle \mathrm{QTcF}<5 \mathrm{~ms}$ with an upper bound $<10 \mathrm{~ms}$, in contrast to the positive comparator, moxifloxacin. LCZ696 administration in healthy subjects was associated with transient asymptomatic increase in HR. Changes in HR have the potential to impact the performance of rate-corrected QT values. Published literature indicates that the Fridericia formula performs better under conditions of alterations in HR, particularly when it is decreased; therefore, a formal adequacy assessment was performed to confirm the superior QT correction method for the study population $[4,15,16]$.

The lack of a relevant effect of LCZ696 on cardiac repolarization is evidenced both by the absence of a relevant mean change in $\triangle \Delta \mathrm{QTcF}$, and the absence of outlier values during categorical change analyses. In addition, central tendency and categorical analyses of the prespecified ECG-derived PR interval and QRS duration did not show any clinically relevant treatment-related changes. The increased mean HR observed at $8 \mathrm{~h}$ following treatment with LCZ696 400 and $1200 \mathrm{mg}$ compared with placebo or moxifloxacin was not dose related and was not temporally related to the maximum drug exposure. It may possibly be related to activity, as the earlier HR measurements on the assessment days were made during bed rest, while later measurements such as at $8 \mathrm{~h}$ post-dose were collected while the subjects were ambulant.

The PK analyses of LCZ696 revealed a dose proportional increase in the exposure of LBQ657 (the active metabolite of sacubitril), whereas the increase in the valsartan exposure was less than dose proportional, similar to the observations reported by $\mathrm{Gu} \mathrm{J}$ et al. [3]. The observed mean $\mathrm{C}_{\max }$ for all three LCZ696 analytes (sacubitril, $7780 \mathrm{ng} / \mathrm{mL}$; LBQ657, $40700 \mathrm{ng} / \mathrm{mL}$; and valsartan, $9360 \mathrm{ng} / \mathrm{mL}$ ) following the administration of a supratherapeutic dose of LCZ696 (1200 mg) in this study exceeded the highest exposures of LCZ696 analytes observed to date at steady state in subjects with severe renal impairment receiving LCZ696 $400 \mathrm{mg}$ once daily for 5 days (sacubitril, $4960 \mathrm{ng} / \mathrm{mL}$; LBQ657, $30650 \mathrm{ng} / \mathrm{mL}$; and valsartan, $5852 \mathrm{ng} / \mathrm{mL}$ ) [17]. The mean maximum QTcF was noted at $1 \mathrm{~h}$ post-dose for both 400 and $1200 \mathrm{mg}$ dose levels, similar to the median $\mathrm{T}_{\max }$ for sacubitril of $30 \mathrm{~min}$ for the $400 \mathrm{mg}$ dose and $1 \mathrm{~h}$ for the $1200 \mathrm{mg}$ dose. In contrast, the $\mathrm{T}_{\max }$ for LBQ657 and valsartan occurred at 2-3 h post-dose.

The upper bound of the two-sided $90 \%$ CI of the modelpredicted regression lines for the relationship between $\Delta \Delta \mathrm{QTcF}$ and concentration of LCZ696 analytes at the supratherapeutic dose were below $10 \mathrm{~ms}$, except for sacubitril, at concentrations
$>15000 \mathrm{ng} / \mathrm{mL}$. However, the observed mean $\Delta \Delta \mathrm{QTcF}$ values, corresponding to sacubitril concentrations $>15000 \mathrm{ng} / \mathrm{mL}$, remained below $10 \mathrm{~ms}$. Sacubitril concentrations are not expected to exceed $15000 \mathrm{ng} / \mathrm{mL}$ upon the administration of single or multiple doses of LCZ696 $400 \mathrm{mg}$ (therapeutic dose). Even in subjects with severe renal impairment, the mean peak plasma concentration of sacubitril after multiple doses of LCZ696 $400 \mathrm{mg}$ once daily for 5 days was $4960 \mathrm{ng} / \mathrm{mL}$ [17], 3-fold lower than the highest individual $\mathrm{C}_{\max }$ of sacubitril following LCZ696 $1200 \mathrm{mg}$ administration in this study. Therefore, the model-predicted values for high exposures to sacubitril are not considered to be of clinical relevance.

LCZ696 (400 mg and $1200 \mathrm{mg}$ ) and moxifloxacin $(400 \mathrm{mg})$ single doses were generally safe and well tolerated.

The overall safety profile in this study in healthy subjects was similar to the known safety profile of LCZ696 [18-20]. There were no repolarization changes on the ECGs and no AE reports that could suggest a potential for a pro-arrhythmic effect of LCZ696.

The major limitation of the present study is that the information was collected in healthy subjects and not in patients with HF, and that the supratherapeutic dose provides modest safety margins of 2.4-fold, 2.9-fold, and 2.0-fold, respectively, for the $\mathrm{C}_{\max }$ of sacubitril, LBQ657, and valsartan compared with patients with severe renal impairment.

\section{Conclusions}

Single therapeutic and supratherapeutic oral doses of LCZ696 (400 and $1200 \mathrm{mg}$ ) did not affect cardiac repolarization, as evidenced by the lack of effect on QTc interval. Moxifloxacin was associated with the expected prolongation of the QT interval, thereby demonstrating assay sensitivity. LCZ696 at 400 and $1200 \mathrm{mg}$ doses was generally safe and well tolerated in this study.

Acknowledgments The authors would like to thank Sreedevi Boggarapu, Novartis Healthcare Pvt. Ltd., Hyderabad, India, for providing writing/editorial assistance. All authors read and approved the final manuscript.

TL, PP, SV, IR JP, PJ, and PC contributed to the study design and/or data interpretation. PP participated in study design and statistical analysis. TL, JP, IR, and PC conducted the study.

The authors would like to thank Dr. Thomas Koernicke (Principle Investigator, PAREXEL International GmbH, Berlin, Germany) for study conduct and iCardiac Technologies Inc., (Rochester, NY, USA) for the input into the protocol development and analysis of ECG parameters.

Compliance with ethical standards The study protocol was approved by the Ethics Committee of the study center. The study was designed and implemented in accordance with the ICH Guidelines for Good Clinical Practice E6 [11] and for Clinical Evaluation of QT/QTe Interval Prolongation and Proarrhythmic Potential for Non-Antiarrhythmic Drugs E14 [12], applicable local regulations, and the ethical principles laid down in the Declaration of Helsinki. 
Conflict of interest THL, PJ, PP, SV, and IR are employees of Novartis. JP and PC were employees of Novartis at the time this study was conducted.

\section{References}

1. 1 Novartis Entresto ${ }^{\mathrm{TM}}$ (sacubitril and valsartan): US pescribing information. 2015. http://www.pharma.us.novartis.com. Accessed on 21 Nov 2015.

2. EMA. Entresto (sacubitril / valsartan) product information. (http:// www.ema.europa.eu/ema/index.jsp?curl=pages/medicines/human/ medicines/004062/human_med_001929.jsp\&mid= WC0b01ac058001d124). Last accessed on 12 Jan 2016.

3. Gu J, Noe A, Chandra P, Al-Fayoumi S, Ligueros-Saylan M, Sarangapani R, Maahs S, Ksander G, Rigel DF, Jeng AY, Lin TH, Zheng W, Dole WP (2010) Pharmacokinetics and pharmacodynamics of LCZ696, a novel dual-acting angiotensin receptorneprilysin inhibitor (ARNi). J Clin Pharmacol 50(4):401-414

4. Isbister GK, Page CB (2013) Drug induced QT prolongation: the measurement and assessment of the QT interval in clinical practice. Br J Clin Pharmacol 76(1):48-57. doi:10.1111/bcp.12040

5. Wysowski DK, Corken A, Gallo-Torres H, Talarico L, Rodriguez EM (2001) Postmarketing reports of QT prolongation and ventricular arrhythmia in association with cisapride and Food and Drug Administration regulatory actions. Am J Gastroenterol 96(6):16981703. doi:10.1111/j.1572-0241.2001.03927.x

6. Cubeddu LX (2009) Iatrogenic QT abnormalities and fatal arrhythmias: mechanisms and clinical significance. Curr Cardiol Rev 5(3): 166-176. doi:10.2174/157340309788970397

7. Redfern WS, Carlsson L, Davis AS, Lynch WG, MacKenzie I, Palethorpe S, Siegl PK, Strang I, Sullivan AT, Wallis R, Camm AJ, Hammond TG (2003) Relationships between preclinical cardiac electrophysiology, clinical QT interval prolongation and torsade de pointes for a broad range of drugs: evidence for a provisional safety margin in drug development. Cardiovasc Res 58(1):32-45

8. Klimas J, Kruzliak P, Rabkin SW (2015) Modulation of the QT interval duration in hypertension with antihypertensive treatment. Hypertens Res 38(7):447-454. doi:10.1038/hr.2015.30

9. Garg S, Narula J, Marelli C, Cesario D (2006) Role of angiotensin receptor blockers in the prevention and treatment of arrhythmias. Am J Cardiol 97(6):921-925. doi:10.1016/j.amjcard.2005.10.028
10. Wang YH, Shi CX, Dong F, Sheng JW, Xu YF (2008) Inhibition of the rapid component of the delayed rectifier potassium current in ventricular myocytes by angiotensin II via the AT1 receptor. Br J Pharmacol 154(2):429-439. doi:10.1038/bjp.2008.95

11. ICH E6 (2015) Guidance for industry; good clinical practice: consolidated guidelines. 1996

12. Food, Drug Administration HHS (2005) International conference on harmonisation; guidance on E14 clinical evaluation of QT/QTc interval prolongation and proarrhythmic potential for nonantiarrhythmic drugs; availability. Notice. Fed Reg 70(202): 61134-61135

13. Varro A, Baczko I (2011) Cardiac ventricular repolarization reserve: a principle for understanding drug-related proarrhythmic risk. Br J Pharmacol 164(1):14-36. doi:10.1111/j.1476-5381.2011.01367.x

14. Hjalmarson A, Fagerberg B (2000) MERIT-HF mortality and morbidity data. Basic Res Cardiol 95(Suppl 1):I98-I103

15. Luo S, Michler K, Johnston P, Macfarlane PW (2004) A comparison of commonly used QT correction formulae: the effect of heart rate on the QTc of normal ECGs. J Electrocardiol 37:81-90. doi:10. 1016/j.jelectrocard.2003.08.030

16. Rowlands DJ (2012) Graphical representation of QT rate correction formulae: an aid facilitating the use of a given formula and providing a visual comparison of the impact of different formulae. J Electrocardiol 45(3):288-293. doi:10.1016/j. jelectrocard.2012.01.003

17. Ayalasomayajula S, Langenickel T, Chandra P et al (2014) Assessment of steady state pharmacokinetics of LCZ696 in patients with renal impairment. Clin Pharmacol Drug Dev 3: $1-59$

18. Kario K, Sun N, Chiang FT, Supasyndh O, Baek SH, InubushiMolessa A, Zhang Y, Gotou H, Lefkowitz M, Zhang J (2014) Efficacy and safety of LCZ696, a first-in-class angiotensin receptor neprilysin inhibitor, in Asian patients with hypertension: a randomized, double-blind, placebo-controlled study. Hypertension 63(4): 698-705. doi:10.1161/HYPERTENSIONAHA.113.02002

19. Ruilope LM, Dukat A, Bohm M, Lacourciere Y, Gong J, Lefkowitz MP (2010) Blood-pressure reduction with LCZ696, a novel dualacting inhibitor of the angiotensin II receptor and neprilysin: a randomised, double-blind, placebo-controlled, active comparator study. Lancet 375(9722):1255-1266

20. McMurray JJV, Packer M, Desai AS, Gong J, Lefkowitz MP, Rizkala AR, Rouleau JL, Shi VC, Solomon SD, Swedberg K, Zile MR (2014) Angiotensin-neprilysin inhibition versus enalapril in heart failure. N Engl J Med 371(11):993-1004. doi:10.1056/ NEJMoa1409077 